value to dichotomise patients into those with preserved $(\geq 50 \%)$ and those with impaired $(<50 \%)$ function. ${ }^{4}$

In all, 522 patients had adequate measurements of ejection fraction, of whom $163(31 \%)$ had values $\geq 50 \%$ and $359(69 \%)<50 \%$. Information on deaths was recorded to April 2000, allowing five year survival status to be determined for all patients. The table shows the characteristics of the two groups and statistical methods.

Five year mortality was substantial in both groups but significantly greater in patients with impaired left ventricular systolic function $(41.5 \%$ v 25.2\%, P < 0.001$)$. Twenty five per cent of patients with preserved function had non-sustained ventricular tachycardia. Both groups had similar SDNN measurements, which were lower than previously shown in age matched healthy control subjects.

\section{Comment}

Mortality is significantly greater in patients with chronic heart failure and impaired left ventricular systolic function than in those with preserved systolic function. However, even the patients with preserved systolic function have a $25 \%$ five year mortality. Therefore, clinical heart failure itself has a poor long term prognosis, irrespective of electrocardiographically determined left ventricular systolic function. Autonomic function was abnormal in both groups, and this, allied to the presence of non-sustained ventricular tachycardia and left ventricular hypertrophy, may contribute to the high mortality found in the patients with preserved systolic function.

Our findings add to those of a recent study by Kitzman et al, who found that patients with chronic heart failure and preserved left ventricular systolic function have similar, but not as severe, pathophysiological derangements to those with impaired systolic function. ${ }^{4}$ These and our data suggest that established treatments for systolic heart failure may also have a role in patients with chronic heart failure and preserved left ventricular systolic function.

Contributors: PAM and MTK conceived the original idea, did the retrieval, analysis, and interpretation of the data, and wrote the paper. MTK helped to collect the raw data. KAAF, JN, and WPB were responsible for the original concept of the UK-HEART study, designed the database, and collected the data on patients; they also reviewed and revised the current paper. AJL and RJP helped with data acquisition and advised on statistical analysis. AJL did a large part of the statistical analysis. AMS helped with the conception of this project, the study design, the interpretation of data, and the revision of the manuscript. MTK is the guarantor for the paper.

Funding: PAM was the recipient of an advanced training scholarship from the British Heart Foundation; MTK is a British Heart Foundation (BHF) intermediate research fellow; and AMS and KAAF hold BHF chairs in cardiology.

Competing interests: None declared.

Ethical approval: Local ethics committees at each participating hospital approved the protocol, and informed written consent was obtained from all patients.

Vasan RS, Benjamin EJ, Levy D. Prevalence, clinical features and prognosis of diastolic heart failure: an epidemiologic perspective. I Am Coll sis of diastolic heart fail

2 Nolan J, Batin PD, Andrews R, Lindsay SJ, Brooksby P, Mullen M, et al. Prospective study of heart rate variability and mortality in chronic heart failure. Results of the United Kingdom heart failure evaluation and assessment of risk trial (UK-Heart). Circulation 1998;98:1510-6.

3 Kearney MT, Fox KA, Lee AJ, Prescott RJ, Shah AM, Batin PD, et al. Predicting death due to progressive heart failure in patients with mild-tomoderate chronic heart failure. J Am Coll Cardiol. 2002;40:1801-8.

4 Kitzman DW, Little WC, Brubaker PH, Anderson RT, Hundley WG, Marburger CT, burger CI, et al. Pathophysiological characterization of isolated diastolic

Bigger JT Jr, Fleiss JL, Steinman RC, Rolnitzky LM, Schneider WJ, Stein PK. RR variability in healthy, middle-aged persons compared with patients with chronic coronary heart disease or recent acute myocardial infarction. Circulation 1995;9:1936-43.

(Accepted 15 April 2003)

\title{
Should same anaesthetist do preoperative anaesthetic visit and give subsequent anaesthetic? Questionnaire survey of anaesthetists
}

\author{
Bruno Simini, Guido Bertolini for the GiViTI group (Gruppo italiano per la Valutazione degli \\ interventi in Terapia Intensiva)
}

The preoperative anaesthetic visit is done to assess the patient's fitness for surgery, to discuss the most appropriate anaesthetic technique, to reassure the patient, to obtain informed consent, and to prescribe premedicant drugs. Patients used to be visited by the doctor who later anaesthetised them, ${ }^{1}$ but the preoperative visit and the subsequent anaesthetic are now seldom done by the same anaesthetist. ${ }^{2}$ Patients would rather be anaesthetised by the doctor who saw them, ${ }^{3}$ but anaesthetists' opinions are unexplored.

\section{Participants, methods, and results}

In June 2002 we sent a questionnaire containing two scenarios to anaesthetists belonging to the Gruppo italiano per la Valutazione degli interventi in Terapia Intensiva (GiViTI), a research network of Italian anaesthesia and intensive care units founded in 1991 to promote research and improve clinical practice. In scenario A, "one patient, one anaesthetist," patients are anaesthetised by the anaesthetist who visited them. In scenario B, "one patient, two anaesthetists," one anaesthetist visits a patient and another physician administers the anaesthetic. We asked anaesthetists which scenario is used in their institution, which one they preferred, and to pick from a list (drawn up by a panel of senior anaesthetists, see box) at least one reason for their choice. Assuming 50\% preferences for both choices (worst scenario for estimating sample size), we needed 170 respondents to give a width of $15 \%$ for the
Ospedale Generale Lucca, Italy Bruno Simini consultant anaesthetist

Laboratorio di Epidemiologia Clinica, Istituto di Ricerche Farmacologiche "Mario Negri," 24020 Ranica (Bergamo), Italy Guido Bertolini senior epidemiologist Correspondence to: B Simini bruno.simini@ virgilio.it

BMJ 2003;327:79-80 


\section{Reasons for choosing each scenario}

Reasons for preferring scenario A (one patient, one anaesthetist)

1. Because in case of litigation, how will responsibilities be attributed to the two anaesthetists involved?

(136 answers; $69 \%$ of respondents)

2. Because preoperative tests and drugs are best ordered by the anaesthetist who gives the anaesthetic $(126 ; 64 \%)$

3. Because anaesthetists should never visit a patient thinking "who cares, it's not me who will give the anaesthetic" (101; 51\%)

4. To avoid the second anaesthetist cancelling an operation for a patient he or she deems unfit but who was judged fit by the first anaesthetist $(82 ; 41 \%)$

5. Because you can't be expected to anaesthetise a patient you think is unfit for surgery, just because another anaesthetist judged him or her fit $(59 ; 30 \%)$

6. Because it's the anaesthetist who gives the anaesthetic who should choose the anaesthetic technique $(40 ; 20 \%)$

7. Because otherwise you are working at a surgical assembly line $(36 ; 18 \%)$

8. Because otherwise no patient-doctor relationship is possible $(33 ; 17 \%)$

9. Because the person who gets the patient's informed consent should give the anaesthetic $(30 ; 15 \%)$

10. Because patients prefer being visited and anaesthetised by the same doctor $(10 ; 5 \%)$

Reasons for preferring scenario B (one patient, two anaesthetists)

1. Because it's easier to organise $(17 ; 9 \%)$

2. Because it forces anaesthetists in a department to adopt uniform preoperative criteria $(16 ; 8 \%)$

3. Because each patient is seen by two anaesthetists $(6 ; 3 \%)$

4. Because it allows sharing of responsibility in case of mishaps $(1 ; 0.5 \%)$

$95 \%$ confidence interval of the percentage of preferences

Within a month 198/262 (76\%) anaesthetists from 99 departments replied. Respondents had a mean age of 45 (SD 7; range 26-62) years and a mean seniority of $15(8 ; 0-33)$ years; $194(98 \%)$ anaesthetists worked in public hospitals. In all, 161 anaesthetists $(81.3 \%$; 95\% confidence interval $75.3 \%$ to $86.1 \%$ ) preferred scenario A, $20(10.1 \% ; 6.6 \%$ to $15.1 \%)$ preferred B (reasons are shown in the box), and $17(8.6 \% ; 5.4 \%$ to $13.3 \%)$ had no preference. Of respondents who chose scenario A, 145/161 (90\%) picked fewer than six reasons for their choice (range 1-9). Eighty nine departments out of 99 $(89.9 \% ; 82.4 \%$ to $94.4 \%)$ used scenario $\mathrm{B}$, and 10 $(10.1 \% ; 5.6 \%$ to $17.6 \%)$ used A.

\section{Comment}

The scheme "one patient, two anaesthetists," enforced in nine tenths of the departments, is preferred by only one tenth of anaesthetists. The vast majority of anaesthetists (like patients ${ }^{3}$ ) prefer the scenario "one patient, one anaesthetist."

Preoperative assessment in Italy is always done by medical anaesthetists but seldom by the one who will administer the anaesthetic. A decade ago it was "accepted as an integral part of the practice of high quality anaesthesia that patients are visited by the anaesthetist who will subsequently anaesthetise them: indeed such a practice is considered as a marker of quality." Anaesthetic standards in the United Kingdom state that "the anaesthetist will normally visit the patient both pre and postoperatively. Unless in emergency or unusual circumstances this is a requirement of the specialty. Ideally this should be carried out by the anaesthetist who is to administer the anaesthetic. Where this cannot be undertaken the anaesthetist should detail in the case notes the reason for the omission."

A high response rate $(76 \%)$ and sending questionnaires to predetermined researchers excludes self selection bias. If non-responders would have chosen scenario $\mathrm{B}, \mathrm{A}$ would still have been preferred by a large majority (161 (61\%) v $84(32 \%)$ out of 262). Our results reflect the opinions of anaesthetists interested in research.

Among reasons given for preferring scenario A no single pattern prevailed-the combination of reasons chosen most often was chosen by $7 \%$ of respondents. This excludes wish bias (the questionnaire pushing respondents in the direction they believe would please the investigators). The single reason cited most in favour of A was the medicolegal one (69\%), and the reason given least often was following the patient's preference (5\%). Does this reflect anaesthetists' current concerns? Reasons given for supporting scenario B were non-clinical: easier organisation and uniformity within departments.

The policy "one patient, two anaesthetists," adopted by most Italian anaesthetic departments, clashes with professional standards and with the opinion of anaesthetists and patients. Why is clinical practice so far from ideal? Is the same happening in other countries and in other disciplines? Current preoperative assessment in Italy is judged by most anaesthetists doing it and patients undergoing it to be done by the wrong anaesthetist.

We thank Marta Cattaneo for her invaluable help.

Contributors: BS and GB designed the study GB coordinated the study and did the statistical analysis. Both authors wrote the paper and are guarantors for the study.

Funding: Mario Negri Institute, Ranica (Bergamo), Italy.

Competing interests: None declared.

1 Egbert LD, Battit GB, Turdoff H, Beccher HK. The value of the pre-operative visit by the anaesthetist: a study of doctor-patient rapport. JAMA 1963; 188:87-9

2 Roizen ME. More preoperative assessment by physician and less by laboratory tests. $N$ Engl J Med 2000;342:204-5.

3 Simini B. Pre-operative visits by anaesthetists. Anaesthesia 2001:56:591.

Nightingale JJ, Lack JA, Stubbing JF, Reed J. The pre-operative visit: its value to the patient and the anaesthetist. Anaesthesia 1992;47:801-3.

5 Royal College of Anaesthetists. Guidelines for the provision of anaesthetic services. Oxford: Hall, 1999:8.

(Accepted 10 April 2003)

\section{Endpiece}

\section{Proof of old age}

The ageing process has you firmly in its grasp if you never get the urge to throw a snowball.

Doug Larsen, American Christian singer

Fred Charatan, retired geriatric physician, Florida 